\title{
Localized cutaneous argyria: A new observation
}

\section{Selma El Kadiri, Hanane Baybay, Rhizlane Chaoui, Sara Elloudi, Fatima Zahra Mernissi}

\author{
Departement of Dermatology, CHU Hassan II, Fez, Morocco
}

Corresponding author: Dr. Selma El Kadiri, E-mail: elkadiri-s@hotmail.com

\begin{abstract}
A 27-year-old female, a radiotherapy technician, was referred to our consultation with a localized gray pigmentation of the perinasal area. The condition had been asymptomatic for its entire duration of 2 years. A dermatological examination found a localized bluish-gray pigmentation in the perinasal area. Dermoscopy revealed an annular bluish-gray patch. Her occupation involved the manufacture and micromanipulation of machines, which required handling pure iron, nickel, copper, and silver with bare hands. She also reported a tic of flaring the nose. A skin biopsy was performed and histology revealed deposits of fine granules in the basal cell layer of eccrine sweat glands and along the elastic fibers of the superficial dermis, conforming with the diagnosis of argyria. The patient was given laser Q-switching treatment and showed a measurable improvement. This case studies a currently rare dermatological curiosity. Argyria is a disease caused by chronic absorption of silver-rich materials. This is the first description of argyria following the manipulation of radiopaque caches with a tic of flaring the nose.
\end{abstract}

Key words: Argyria; Cerrobend; Occupational argyria; Skin pigmentation

\section{INTRODUCTION}

Argyria is an uncommon clinical condition caused by prolonged skin exposure to silver. Two known types of argyria exist: localized and generalized. Localized argyria has been reported to be the result of using topical medication and inadvertently implanting in the skin objects that contain silver. Several different types of exposure-accidental, therapeutic, occupational, and environmental-routes of administrationoral, intranasal, and percutaneous-and intervals of exposure-from 8 months to 5 years-have been described. The diagnosis is reached by histopathology, although certain cases may necessitate the identification of the presence of metal by electron microscopy (EM).

The following case report studies a patient with localized argyria caused by manipulation of focused custom caches (Cerrobend).

\section{CASE REPORT}

A 27-year-old woman showed a localized bluish-gray pigmentation in the perinasal area asymptomatic for 2 years (Fig. 1). The patient denied the use of drugs: phenothiazines, antimalarials, amiodarone, and minocycline. She did not report the use of a nasal decongestant or an antiseptic. Two years after beginning her professional occupation, she noted the appearance of bluish macules in the perinasal area. Rhinoscopy did not find any gray pigmentation on the anterior part of the nose. Dermoscopy revealed an annular bluish-gray patch with blurred borders (Fig. 2). We performed a biopsy and found deposits of fine granules in the basal cell layer of eccrine sweat glands and along the elastic fibers of the superficial dermis (Fig. 3). Since the patient admitted to manipulating focused custom caches containing silver and having a tic of flaring the nose, a final diagnosis of occupational argyria was established. The patient was treated with laser Q-switching and showed a measurable improvement (Fig. 4).

\section{DISCUSSION}

Argyria is a rare disease caused by chronic absorption of silver-rich materials [1]. Skin pigmentation is caused

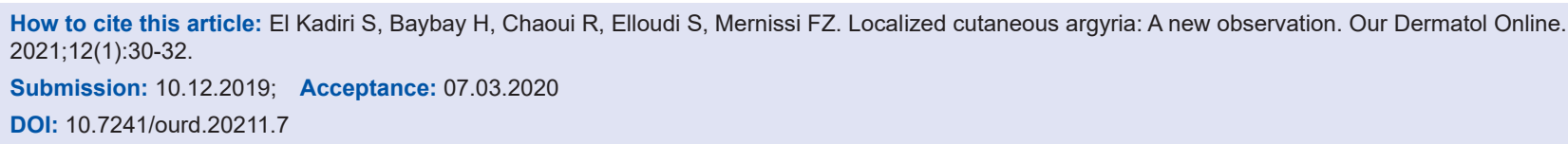




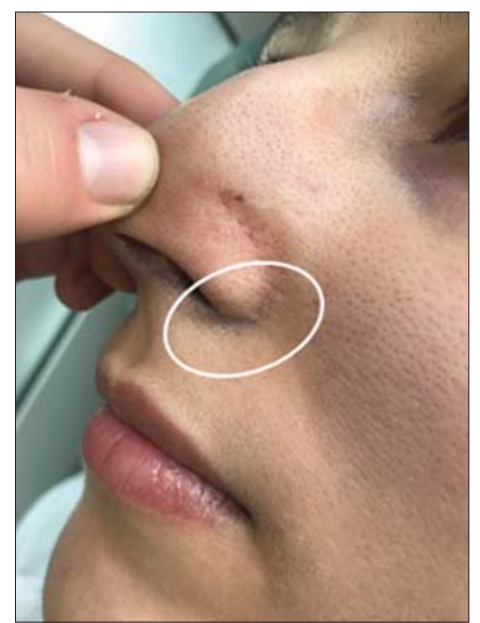

Figure 1: Localized bluish-black pigmentation in the perinasal area.

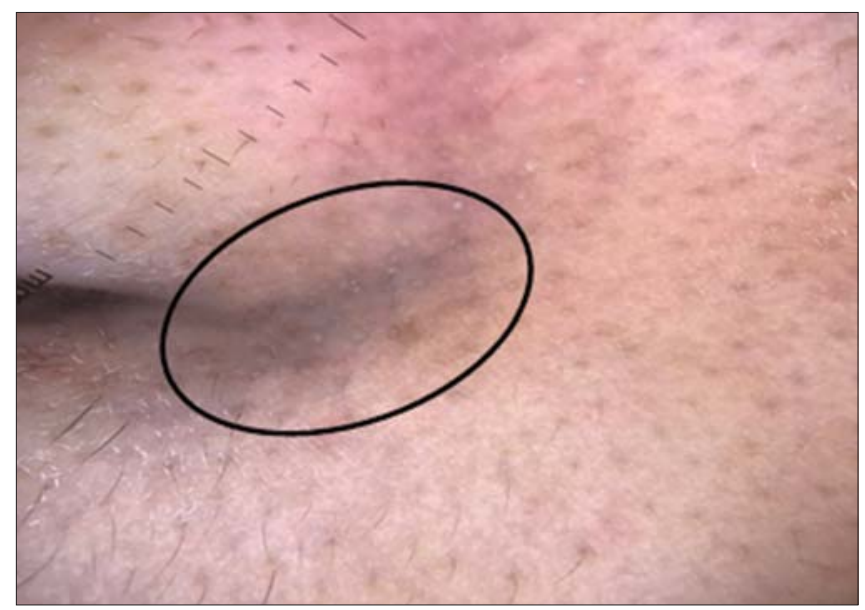

Figure 2: Dermoscopy showing annular structures on a gray background area (black circle).

not only by silver deposition-in sulfite or selenite forms - in the dermis but also, according to some, by stimulation of melanin synthesis [2].

In localized argyria (LA), lesions may appear as asymptomatic slate, gray, or blue macules resembling blue nevi. The reason as to why the gray color is more evident in photoexposed skin areas is unknown. It is believed that silver assumes a brownish-black hue through a chemical reduction reaction or through a photomediated exacerbation of its stimulatory effect on melanin synthesis [3].

These compounds are deposited following slow tissue flux and are captured by elastic fibers and the basement membrane before reaching the epithelium. The bluish-gray color of dermoscopic structures was most probably produced via the Tyndall effect, which gives the appearance of bluish-gray pigment located deep within the dermis. The bluish-gray annular

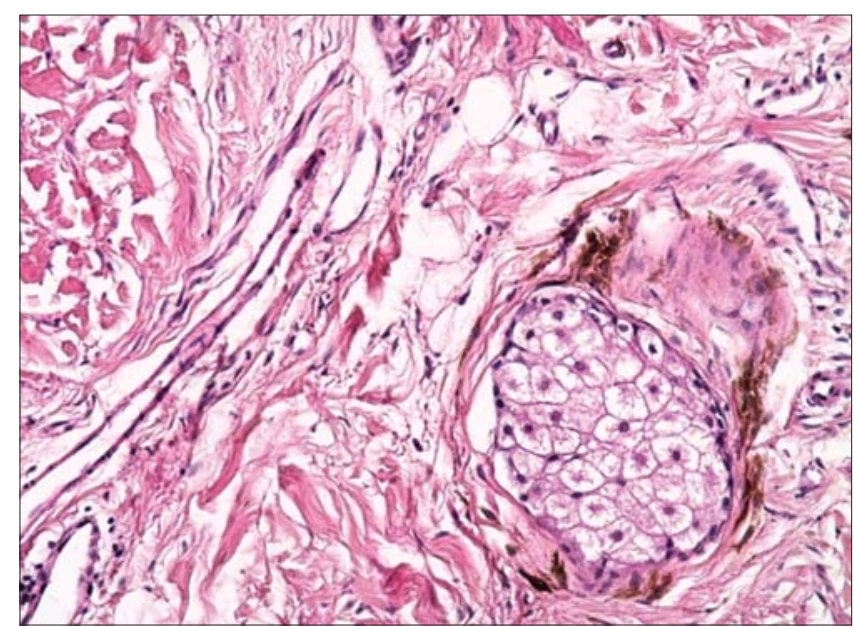

Figure 3: Histology showing deposits of fine granules along the elastic fibers of the superficial dermis.

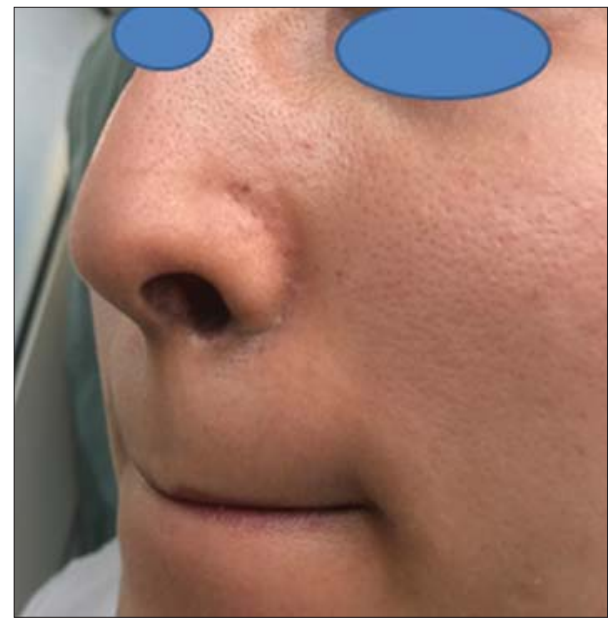

Figure 4: Control image after laser.

structures were observed by dermoscopy due to the presence of pigment deposition around eccrine glands. A histopathological examination showed an accumulation of brownish-black granules with no appreciable inflammatory infiltrate; such granules lie in compact bands parallel to the mucosal surface and/ or in black cloud-like aggregates close to the surface. The basic requirements to identify such granules as an exogenous pigment are their Perls stain negativity and persistence after tissue section bleaching [4]

Different treatments can be proposed to this benign condition; these may include topical depigmenting agents such as hydroquinone, but they give little improvement. However, in most reported cases, laser Q-switching led to noticeable improvements [5].

To the best of our knowledge, this is the first description of argyria following manipulation of radiopaque caches 
with bare hands. Radiation therapy caches contain tin, an alloy of silver and copper.

Our case highlights the adverse consequences of manipulating focused custom caches that may be ignored in a limited clinical setting.

\section{CONCLUSION}

Localized argyria is a benign condition unassociated with systemic disorders or malignant development. Even so, a manifest location, such as the face, can disturb and alarm patients.

\section{Consent}

The examination of the patient was conducted according to the principles of the Declaration of Helsinki.

The authors certify that they have obtained all appropriate patient consent forms, in which the patients have given consent for images and other clinical information to be included in the journal. The patients understand that their names and initials will not be published and due effort will be made to conceal their identity, but that anonymity cannot be guaranteed.

\section{REFERENCES}

1. Ferrara G, Filosa A, Mariani MP, Fasanella L. Occupational argyria of the nasal mucosa. Head Neck Pathol. 2018;12:252-4.

2. Bracey NA, Zipursky JS, Juurlink DN. Argyria caused by chronic ingestion of silver. CMAJ. 2018;190:E139.

3. Lencastre A, Lobo M, João A. Argyria-case report. An Bras Dermatol. 2013;88:413-6.

4. Enei ML, Paschoal FM, Valdés R. Argyria mimicking blue naevus: dermoscopy features. An Bras Dermatol. 2013;88:452-5.

5. Griffith RD, Simmons BJ, Bray FN, Falto-Aizpurua LA, Yazdani Abyaneh MA, Nouri K. 1064 nm q-switched nd: YAG laser for the treatment of argyria: a systematic review. J. Eur. Acad. Dermatol. Venereol. 2015; 29: 2100-3.

Copyright by Selma El Kadiri, et al. This is an open access article distributed under the terms of the Creative Commons Attribution License, which permits unrestricted use, distribution, and reproduction in any medium, provided the original author and source are credited.

Source of Support: Nil, Conflict of Interest: None declared. 